\title{
UM MÉTODO PARA INVESTIGAR A CONSCIÊNCIA: DO INTRAPSICOLÓGICO AO INTERPSICOLÓGICO
}

\author{
Inara Barbosa Leão \\ Universidade Federal de Mato Grosso do Sul, Campo Grande, Brasil
}

\begin{abstract}
RESUMO: O texto apresenta reflexões sobre a base teórica e a prática da técnica de investigação de conteúdos, processos e mediações presentes na constituição da consciência humana elaborada pela professora Sílvia Tatiana Maurer Lane, denominada de Análise Gráfica do Discurso. Para tanto, apresentamos algumas reflexões sobre os seus fundamentos epistemológicos, teóricos e metodológicos a partir das publicações, aulas e das orientações recebidas da professora Sílvia Lane. Nestas privilegiamos as contribuições da Teoria Psicológica Laneana e da Teoria Psicológica Sócio-histórica, bem como tentamos demonstrar como proceder a utilização da técnica.
\end{abstract}

PALAVRAS-CHAVE: Sílvia Lane; análise gráfica; linguagem; consciência.

\section{A METHOD FOR INVESTIGATING THE CONSCIENCE: FROM THE INTRAPSYCHOLOGICAL TO THE INTERPSYCHOLOGICAL}

ABSTRACT: This paper presents some thoughts on Sílvia Lanes Graphic Discourse Analysis, discussing the theoretical bases and the technique of content investigation, processes and mediations present in the constitution of human consciousness. For this, we present some reflections on its epistemological, theoretical and methodological fundamentals from Sílvia Lane's publications, seminars and advisory sessions, highlighting Lanean Psychological Theory and Social-Historical Psychological Theory, as well as demonstrating how to proceed in using the technique.

KEYWORDS: Sílvia Lane; graphic analysis; language; consciousness.

Os pressupostos teóricos que nos orientam nesta exposição fundamentam-se nos dezesseis anos de convivência e aprendizado que mantivemos com a Professora Sílvia Lane. Com ela entendemos, primeiramente, que a base epistemológica, teórica e metodológica necessária para a Psicologia Social está dada na dialética materialista histórica. Ela nos explicava que para construir conhecimento científico é necessário apreender o objeto de estudo como resultante do processo das relações materiais e dos condicionamentos gerados pelas características do momento histórico em que se dão.

Portanto, a investigação de um fenômeno particular, estabelecida nas condições mencionadas, exige que nos apoiemos em teorias, métodos e técnicas que, partindo da sua manifestação empírica, nos conduzam ao desvelamento das inter-relações implícitas que o determinam. Isso significou reaprender que não há conhecimento inválido, desde que possamos analisá-lo e reconstituí-lo em sínteses promotoras da verificação de quais são os aspectos do já elaborado que se mostram inverossímeis ao serem confrontados com a realidade material e histórica do momento no qual estabelecemos tal confronto.

Foi em busca dessa possibilidade que a Sílvia Lane criou uma técnica que nos permite observar estes preceitos na pesquisa psicológica: a Análise Gráfica do Discurso. Até a nossa última conversa, em 2006, ela ainda estava preocupada com o desenvolvimento do método e da técnica, devido às possibilidades que entendia que eles possuem. Foram duas as maiores preocupações que apontou: a necessidade de desenvolver um suporte de software para a sua utilização e a continuidade das pesquisas com a Análise Gráfica considerando as linguagens computacionais.

Certamente, as duas intenções são importantes e devemos persegui-las. Porém, para tanto, temos nos defrontado com uma dificuldade fundamental: Sílvia não nos deixou muitas indicações que contemplassem todos os seus pensamentos e práticas sobre a Análise Gráfica do Discurso, além do texto publicado na Revista Psicologia \& Sociedade, em 1989, sob o título: "Uma análise gráfica do discurso". Temos considerações esparsas, nas quais encontramos as preocupações e explicações elaboradas até o momento da redação dos mesmos. Ainda que entendamos ter sido esta a sua posição, por compreender que nada está definitivamente "dado", uma vez que estamos submetidos aos processos históricos e à dialética da vida; não há um escrito que organize e apresente sistematicamente os pontos que tinha como definitivos e esclarecidos.

O que apresentamos aqui são os princípios e orientações que fomos recolhendo dos seus ensinamentos sobre a Análise Gráfica do Discurso. São apenas aqueles que tivemos a possibilidade de retermos nas nossas buscas, 'conversas' e na elaboração de nossos trabalhos, a dissertação de Mestrado e a Tese de Doutorado (Leão, 
1989, 1999), realizados sob a sua orientação. Entendemos que outros devam ter conhecimentos diversos, oriundos da especificidade das suas atividades e contatos com a Sílvia.

\section{Fundamentos Teóricos}

"Toda psicologia é social, o que significa que cada área específica da psicologia deve assumir dentro de sua especificidade a natureza histórico-social do ser humano, porém, sem perder a sua qualidade de sujeito da história" (Lane, 1989, p. 19).

Segundo Blanck (1987), a Psicologia Social Laneana ou A "Escola de São Paulo" é uma Psicologia Social brasileira, baseada na pesquisa empírica e teórica. Que se caracteriza "desde una perspectiva marxista no ortodoxa y com los desarollos más continuados de la escuela de São Paulo.” (p. 226).

Os pressupostos e objetivos desta Escola ou Teoria Laneana encontram-se sintetizados no Livro "Sílvia Lane", elaborado por Sawaia (2002) para a Coleção Pioneira da Psicologia Brasileira, organizada pelo Conselho Federal de Psicologia. Neste, seu trabalho é caracterizado como uma teoria crítica que explicita a sua intencionalidade de interpretar o mundo para transformá-lo, o que significa que ela defendia: a indissociabilidade entre teoria, metodologia, prática, pressupostos epistemológicos e éticos. Em termos epistemológicos, parte de uma postura materialista-histórico-dialética, o que implica uma concepção de ser humano como produto e produtor da história, ou seja, o homem irá se constituir como tal a partir do momento em que ele rompe a escala filogenética, dando início a um processo ontogenético, decorrente de dois acontecimentos fundamentais: a descoberta da ferramenta e o desenvolvimento da linguagem (Sawaia, 2002).

Por isso nos propõe que o objetivo da Psicologia Social é conhecer o indivíduo no conjunto das relações sociais, tanto naquilo que lhe é específico, próprio da manifestação do seu grupo e inerente à sociedade a qual pertence como no que é de sua criação; conhecê-lo na dialética subjetividade e objetividade e no diálogo interdisciplinar.

Em decorrência, apontava-nos que as categorias analíticas do psiquismo humano são as emoções, a consciência, as atividades e a identidade; orientadas pela idéia hegeliana de mediação, para explicar a relação homem-sociedade. Aquelas se oferecem à análise através dos objetos de estudo empíricos, que são a linguagem e o grupo, os quais constituem as mediações principais entre o homem e a sociedade. Ambos unem os homens, de forma universal, mas se particularizam pelas especificidades histórico-culturais. Assim, estabelecem a mediação entre o social e a subjetividade.

\section{Considerações Sobre o Método}

A metodologia decorrente daquela postura estipula que as pesquisas devem partir de dados empíricos para se chegar ao concreto, ou seja, à essência do fenômeno psicológico, mas não na perspectiva verificacionista, pois entende que o conhecimento não é neutro e contido no empírico, mas um produto histórico. Portanto, é uma construção coletiva e, como tal, o seu entendimento ou desenvolvimento requer uma metodologia que seja participativa e qualitativa. Para tanto, as pesquisas devem ser realizadas "com" a população envolvida para "conhecer as pessoas, seus problemas e emoções e potencializá-las à emancipação" (Lane \& Sawaia, 1995, p. 75).

Na indicação sobre as implicações metodológicas das Categorias Fundamentais da Psicologia Social, os pressupostos adotados por ela exigiam atingir o concreto: "o indivíduo como manifestação da totalidade histórico-social" (Lane \& Codo, 1987, p. 45). E, estas condições podem ser contempladas pelas categorias: atividade, consciência e personalidade que permitem a análise do fato psicológico e podem ser apreendidas pela linguagem, pois é

O discurso produzido pelo indivíduo, que transmite a representação que ele tem do mundo em que vive, ou seja, a sua realidade subjetiva, determinada e determinante de seus comportamentos e atividades (Lane \& Codo, 1987).

Portanto, é para apreendermos a amplitude da consciência e as implicações ideológicas que utilizamos o discurso individual, elaborado na relação dos sujeitos pesquisados com o pesquisador. E cuja análise deve ser processada a partir das categorias que se manifestam neste mesmo discurso e "que o esgotem em todos os significados possíveis, tanto em relação ao que foi dito como ao "não-dito"” (Lane \& Codo, 1987, p. 45-46). Para tanto, nos recomendava que "o importante é o caráter $a$ posteriori das categorias que permite elaborar uma 'síntese precária'” (p. 46), a qual orientará o aprofundamento das análises.

Ao adotar estes procedimentos alterou o entendimento da "amostragem", demonstrando que na Psicologia Social:

... não se procura a generalização, mas sim a especificidade dentro de uma totalidade e, portanto, os indivíduos estudados são escolhidos em função de aspectos e condições consideradas significativas e que muitas vezes não podem ser pré-definidas, mas que emergem da própria análise que vem sendo feita. (Lane \& Codo, 1987, p. 46).

Indicou ainda que tais entendimentos implicam na adoção da práxis como um requisito da análise, o qual 
deve garantir que se partindo do empírico realize-se a análise, se teorize e retorne-se ao empírico. Entretanto, alertava que esta possibilidade dependia de mudanças na relação pesquisador-pesquisado, a qual deveria permitir que ambos se colocassem como sujeitos do processo e simultaneamente objetos da mesma ação, condições estas dadas, inicialmente, nas relações grupais. Portanto, a pesquisa exige a análise das atividades desenvolvidas pelo grupo e que determinam o discurso produzido pelos sujeitos membros. Para este nível de apreensão é necessária a Observação-Participante, técnica fundamental por indicar a relação entre o discurso e a ação dos sujeitos. Daí, sintetizou as suas recomendações para a pesquisa em Psicologia Social:

(1) as definições e conceitos apriorísticos são dispensáveis, quando não, restritivos para a atividade de pesquisar; (2) por outro lado, categorias que nos remetem aos vários níveis da análise permitem chegar à materialidade do fato, ao concreto que está sob o empírico aparente; (3) a pesquisa como "práxis" implica, necessariamente, intervenção e acumulação de conhecimentos; (4) as lacunas no conhecimento são tão importantes quanto o conhecido, se não mais, pois são elas que permitirão aprofundar e rever as análises já realizadas. (Lane \& Codo, 1987, p. 47).

Ao apontar a linguagem e os grupos como os mediadores principais da relação dos indivíduos com a sociedade, Sílvia nos indicou que encontrou na própria Psicologia os elementos dessa sua conclusão e o fez ao analisar e superar os conteúdos do materialismo mecanicista contidos nas Teorias Psicológicas. E, na sua síntese, destacou que de Skinner conservou a relação homem-ambiente, o controle que este exerce sobre o comportamento e a demonstração de que o reforço positivo é universal; de Mead, as suas concepções sobre o outro generalizado e o interacionismo simbólico, as explicações sobre o papel da cultura na particularização do comportamento; de Osgood, a abordagem da relação universal/particular, com sua teoria do Diferencial Semântico, pois suas pesquisas realizadas em trinta culturas diferentes para obtenção do significado afetivo da palavra, constataram três dimensões universais da mesma: um fator de valor, outro relativo à potência e um terceiro, a atividade. Ao mesmo tempo a pesquisa revelou as diferenças sociais e culturais dos significados atribuídos por grupos socialmente diferenciados.

Portanto afirma que:

A linguagem se apresentava como um ponto-chave a ser deslindado, não como algo reificado como os lingüistas o faziam, mas sim como algo dinâmico, construído historicamente pela sociedade e desempenhando um papel fundamental, tanto no desenvolvimento dos indivíduos como na sua inserção em grupo sociais. (Lane \& Sawaia, 1995, p. 69).
Na continuidade das investigações da função da linguagem destaca a contribuição da Teoria de Representações Social de Moscovici e Jodelet e das análises de discurso de Pêcheux.

Este percurso vai permitir a criação da técnica que ela denominou de "Análise Gráfica do Discurso", a qual garante, fundamentalmente, "detectar os núcleos de pensamento que geraram o discurso sem esfacelá-lo" (Lane \& Sawaia, 1995, p. 75-76).

Na construção desta técnica, a contribuição do pensamento de Vigotsky (1972, 1987, 1988, 1991, 1993) já é evidenciada, principalmente no que diz respeito à categoria de mediação, que permite apreender a superação de um fenômeno pelo outro; como nos processos psicológicos que levam à passagem da objetividade para a subjetividade, tornando a primeira parte integrante e causa imanente da segunda. Também, a função dos significados sociais embasa a elaboração da Análise Gráfica por mostrarem o elemento lingüístico que explica a constituição da consciência a partir da relação entre o homem e a sociedade. Isto nos foi explicitado pela sua afirmação sobre esse apoio encontrado nas idéias vigotskianas:

Suas pesquisas e análises demonstram a mediação fundamental que a linguagem exerce na constituição do psiquismo humano, em especial na consciência e de sua vinculação com a atividade. Por outro lado, a linguagem medeia o processo histórico, pois ela é aquilo através do que se generaliza a experiência sócio-histórica da humanidade. (Lane \& Sawaia, 1995, p. 73).

A partir daí estávamos prontos para entender que os métodos de pesquisa e análise do desenvolvimento das Funções Psíquicas Superiores dos homens, calcados nas teorias psicogenéticas, recomendam procedimentos técnicos que possibilitem a localização das suas gêneses e a reconstrução dos processos de elaboração e transformações estruturais suscitadas pelas atividades práticas e pelas aprendizagens. Para tanto os procedimentos técnicos devem permitir o desvendamento dos processos psicológicos comumente encobertos pela atividade cotidiana e o acesso aos conteúdos e seus movimentos no curso real da constituição da consciência.

E concordamos que a Análise Gráfica do Discurso é uma das técnicas que se mostra eficiente para a investigação da consciência. Pois os:

relatos de histórias de vida, nos quais o discurso livre reflete as representações conscientes que o indivíduo faz de si e do mundo que o cerca, constituem o dado empírico a partir do qual podemos detectar os componentes ideológicos, emocionais, as contradições e o próprio movimento do pensamento que engendra o discurso. (Lane, 1989, p. 7). 
Colocava-se, então, a questão da origem dos significados sociais e dos sentidos individuais. Esta indagação, normalmente se apresenta na busca da especificação da gênese das propriedades semânticas dos símbolos mentais, pois, mesmo supondo que as representações mentais sejam objetos físicos, linguagens, permanece a questão de como os objetos físicos podem ter semânticas e referirem-se uns aos outros. Vigotsky, assim como Wittgenstein e Mead, explicaram que os significados e sentidos se estabelecem mediante seu uso socialmente coordenado; é a hipótese da origem social da mente, da consciência. Estas respostas têm indicado que é a partir da linguagem socialmente dada, a partir da linguagem de uso público, imbricada em formas de vida que se constrói a subjetividade.

Tal elucidação superou a crítica apresentada a alguns enfoques da Psicologia Social que consideram apenas as explicações intrapessoais e ignoram que a produção e recepção do significado é um processo interpessoal; pois, a atividade dos homens assimila a experiência da humanidade. Entendemos, então, que os processos mentais humanos (os Processos Psicológicos Superiores) adquirem uma estrutura necessariamente unida a significados formados sócio-historicamente e a métodos transmitidos por outros no processo do trabalho cooperativo e da interação social. Por isso, mesmo o pensamento não falado pressupõe uma comunicação organizada entre indivíduos.

Uma premissa central aqui é que a intersubjetividade precede à subjetividade: $\mathrm{o}$ autoconhecimento resulta do entendimento dos outros aspectos da realidade. E, assim como a ação e o pensamento podem derivar-se da determinação biológica dos seres humanos, os significados e sentidos partem do processo histórico. Isto esclarece que as maneiras pelas quais os indivíduos percebem a si mesmos, se relacionam com os outros, e as formas e conteúdos de seus processos de autoconsciência, são permitidos, mantidos e reproduzidos por processos sociais.

Por isso a Teoria Socio-Histórica pode afirmar que "as formas mais complexas da vida consciente do homem . . . têm sua suas origens . . . não nas profundezas do cérebro nem nas profundezas da alma, mas nas condições externas da vida, e em primeiro lugar, da vida social" (Luria, 1992). E, que a divisão social do trabalho muda as características do comportamento dos homens ao criar a necessidade de uma comunicação através da linguagem.

Por estes fundamentos as investigações em Psicologia só alcançam resultados fiáveis quando se mantêm na perspectiva dialética e consideram pontos fundamentais como os pressupostos que Vigotsky propôs na sua metodologia, denominada de Método Instrumental. A partir dele pudemos discutir com a Sílvia, durante a elaboração da Tese de Doutorado (Leão, 1999), as possibilidades abertas pela Análise Gráfica do Discurso para a aplicação do método vigotskiano. Concluímos, então, que o Método Instrumental por ser subjetivo-objetivo funcional, abarca os pontos de vista descritivo e funcional. Parte da unidade dos processos psíquicos e fisiológicos e, por meio da abstração, o processo psíquico é separado ou retirado do psicofisiológico, porém, considerando que unicamente integrados é que eles adquirem significado e sentido. Tal como Vigotsky propunha, concordamos que nos casos em que há influência dos processos psíquicos (como o terror, a aflição, a alegria, etc.) nos corporais, os fatos se transmitem em sua maior parte fielmente, uma vez que o processo fisiológico correspondente a essa impressão e constitui com ela um todo.

Considerando os elementos acima, tínhamos a coincidência entre o método e a técnica de Análise Gráfica quanto ao que Vigotsky denominou em seu enfoque teórico de 'instrumental', 'cultural' e 'histórico'. E, também, a confirmação que as Funções Psicológicas Superiores incorporam estímulos auxiliares produzidos pelos indivíduos, como se observa nas características imediatas dos processos de estímulo-resposta. Portanto estávamos todos de acordo que:

Os indivíduos modificam ativamente os estímulos presentes diante deles, e deste modo os utilizam como instrumentos de conduta. Fazem isto para mudar as condições do meio e assim controlar sua própria conduta: - introduzindo mudanças no meio os indivíduos constroem seus próprios processos psicológicos. (Blanck, 1987, p. 113).

Também, Luria (1992) nos explicava que o termo 'cultural' se refere às maneiras estruturadas pelas quais as sociedades proporcionam aos sujeitos os objetivos e os instrumentos para atingi-los. E um dos mais importantes destes instrumentos inventados pela humanidade é a linguagem. Já a condição 'histórica' se confunde com a 'cultural'.

Daí confirmamos que com a Análise Gráfica dos discursos podemos evitar partes desnecessárias da inferência individual por apreendermos os elementos que nos permitem a consecução dos seguintes objetivos: (a) localizar, através dos discursos, os núcleos de consciência que foram construídos e/ou desenvolvidos pelos sujeitos durante as suas atividades específicas de produção; (b) acompanhar e analisar a influência dos diferentes aspectos subjetivos, expressos no sentido das palavras, para a organização das consciências e das atividades desenvolvidas nas interações; (c) demonstrar o movimento de alteração dos conceitos, relacionando suas expressões, significações e sentidos. 


\section{Análise Gráfica do Discurso}

Estas constatações reforçaram o que Sílvia Lane nos mostrou sobre a aplicação e desenvolvimento da técnica de "Análise Gráfica do Discurso", destacando que esta permite localizar "graficamente os núcleos do pensamento, através das palavras que se repetem (ou dos sinônimos), mas seguindo a continuidade do discurso, utilizando a sequiência dos números para cada unidade de significação (sujeito e predicado)" (1991, p. 8).

A Análise Gráfica do Discurso visa ainda à exploração de aspectos subjetivos, constituintes da consciência individual. Porém, deve-se observar que nem todas as propriedades dos indivíduos, ainda que tenham origens sociais, são propriedades estruturais de um coletivo. Ao contrário da concepção cartesiana, a concepção vigotskyana implica que o discurso lingüístico: seria o desdobramento, desenvolvimento coletivo e público da interação simbólica que daria forma ao pensamento.

E, tal como Lane, Páez, Valencia, Morales, Sarabia e Ursua (1992), destacam que na análise da linguagem identificam-se dois pontos narrativos diferentes, subjacentes ao positivismo e ao antipositivismo e à importância da linguagem. Estes se devem às posições metateóricas e às concepções diferentes da cultura. Conseqüentemente, o que se propõe como explicação é diferente: umas, nomotéticas, preditivas, gerais, causais; as outras interpretativas, contextuais e intencionais-subjetivas. Metodologicamente, a perspectiva positivista, da narração na terceira pessoa, se centra em medidas transculturais e quantitativas e, a perspectiva antipositivista, da narração na primeira pessoa, se baseia em medidas culturalmente situadas e qualitativas.

Porém, a linguagem e os significados não são coisas subjetivas privadas, mas, coisas públicas e intersubjetivas. Não se trata de crenças convergentes, ou de um consenso normativo ou de valor. Um alto nível de significado intersubjetivo é congruente com divisões e conflitos, sem que os sujeitos tenham dúvidas sobre o que os separa. Significados comuns se encontram integrados na linguagem de uma comunidade e em todas as formas em que os membros de tal comunidade podem falar, porem-se de acordo ou não, dar sentidos, pedir, descrever rebelarem-se ou investigar a realidade social construída por meio de tal linguagem.

Tal como Sílvia Lane procedeu, também alertam (Páez et al., 1992, p. 183) que no trabalho com a linguagem "a preocupação maior deve se centrar em evitar a passagem de elementos epistemológicos aos ontológicos, o que promove a redução da realidade social à lingüística”. Isto é particularmente provável na tradição lingüística-hermenêutica nas ciências sociais, que supõe que, se os produtos e práticas sociais dependem de definições lingüísticas e ideológicas, estas podem ser analisadas exaustivamente mediante um exame de seus aspectos conceituais.

Igualmente, têm proposto atentar para o fato que:

como em geral os objetos sociais são mediados lingüisticamente, são lingüísticos, e se são lingüísticos não é necessário referir-se a nada extralingüístico para explicá-los. Este equívoco é mais comum na etogenia, na análise do discurso e no construtivismo social, onde este erro aparece como um fundamentalismo interpretativo, no qual o conhecimento psicossocial se mantém no nível das narrações autointerpretativas que os sujeitos fazem de suas ações e de seus produtos. (Páez et al., 1992, p. 183).

Outro erro é que, ao centrar-se no uso retórico da linguagem e no exame crítico do vocabulário de ação, e outros recursos lingüísticos das culturas e subculturas sofre-se várias limitações. A primeira é cair no relativismo cultural extremado, no contextualismo dispersivo. A segunda é de cair no círculo hermenêutico sem referência à conduta e narrado na terceira pessoa, etc.: usar a fala sobre a linguagem para entender a que se refere a própria linguagem, e como a fala é um uso retórico da linguagem não se alcança nenhuma explicação fundamental.

Há ainda uma determinação de entendimento na qual todo fenômeno psicossocial deve ser estudado a partir da linguagem, ainda que este fenômeno seja também uma fonte de confusão ou seja: partindo-se da base de que as estruturas sociais não existem independentemente das concepções e práticas lingüísticas dos atores, dos significados que eles lhes atribuem conforme as suas interações e relações sociais e que se conhece mediante a linguagem, se dissolve a intransitividade da estrutura social e se reduz todas as estruturas sociais a componentes lingüísticos consensuados. Este erro consiste em passar de elementos de condições de conhecimento a elementos de existência. Porque

a estrutura social se pode conceber, por suas caracte-
rísticas de emergência, de preexistência, de poder cau-
sal e de condição necessária para a individualização
e ação humanas, como um objeto natural, existente
independentemente dos seres humanos, ainda que ba-
seado em suas atividades, nos significados associa-
dos a elas e de um caráter relativamente durável-as
limitações sócio-históricas das tendências causais-
estruturais. (Páez et al., 1992, p. 187-188).

Em síntese, também na análise dos discursos temos que atentarmos que pensamento e linguagem constituem um conjunto imbricado, conformando um processo que emerge da condição humana e a caracteriza. Daí a linguagem ganhar seu significado de produção coletiva. 
Dado que os processos de linguagem estão internalizados, sua influência se estende ao âmbito geral do comportamento, pelo que aparecem atividades complexas não existentes nas formas inferiores de vida.

Portanto, a investigação a partir da linguagem discursiva exige a organização de um corpo empírico, o qual, em geral, é fornecido por entrevistas. Em nossa prática, elas obedecem a um roteiro semi-estruturado elaborado em função da hipótese, objetivos e fundamentos teóricometodológicos que orientam a investigação.

Estas entrevistas, como instrumento de coleta de dados, exigem que, além das prescrições formais para as suas realizações, cuidemos de apresentar aos entrevistados a explicação da sua finalidade e a forma como serão posteriormente analisadas, pois, apesar do roteiro, alguns aspectos são mais explorados, conforme eles se mostrem significativos, enquanto outros são negligenciados ou substituídos por temas que eles introduzam ou que se 'perceba' como importantes. Portanto, todas as entrevistas são longas, já que são pontuadas pelas experiências e idéias sobre o tema em investigação. São estas possibili- dades que lhes conferem a qualidade de produções únicas, que mesmo que se tente obtê-las novamente, com as mesmas pessoas e sobre os mesmos assuntos, não se reapresentarão.

Após a realização das entrevistas, as gravações devem ser transformadas em textos. Anteriormente, fazíamos as transcrições das fitas; atualmente, as gravações digitais permitem a transferência direta para o computador, cujos programas convertem o áudio em texto. Em alguns casos, após a verificação da qualidade dos dados apresentados. É necessário que se realize novo contato com os entrevistados, em geral, para esclarecimento da grafia de nomes ou outros elementos mencionados e que apresentaram dificuldades de entendimento nas gravações.

Com as entrevistas transcritas, a organização dos dados para a análise exige a identificação e enumeração das Unidades de Significação; estas são apresentadas enquanto frases na sequiência do relato. Em seguida são assinaladas as palavras que se repetem ou seus sinônimos, que indicarão em torno de quais temáticas o discurso foi elaborado. Como no exemplo abaixo:

Eu entendo que criatividade é você dá soluções diferentes do quê, do quê a maioria das pessoas dão./ É..., vamos pensar assim: não sei se você lembra aquela... tem uma brincadeira que se faz com uma fotografia, com um desenho de Jesus Cristo crucificado?/ A... cara dele, é... um negócio assim..., /uns tons de preto e branco que quando você olha para a figura e parece uma figura que não viu nada e, quando, você se aproxima da figura, muito próximo, e aí vai se afastando, a imagem do Cristo vai se formando né!?/ Eu acho que criativo é mais ou menos isso./ Criativo é...,/ criatividade é quando você consegue enxergar uma coisa que a maioria das pessoas não conseguem enxergar/, no sentido de criar coisas né?!/ ... Ser criativo é isso!/ No sentido de..., de... criar coisas,/ do... solucionar coisas que os outros não dão conta./ Pensamento criativo é..., é você constantemente tá fazendo isso./ Ou seja, é você tá pensando as coisas não da maneira óbvia,/ que todo mundo tá pensando./ Você tá pensando de uma outra maneira,/ de uma maneira mais eficaz, mais interessante./ O quê eu entendo por pensamento criativo é isso!/ Os fatores que favorecem ou dificultam o desenvolvimento da criatividade?/ Não./ Eu acho que o trabalho...,/ eu acho que o trabalho do Curso, a Grade Curricular de um curso, de um modo geral, ela trabalha muito mais é... para dificultar a criatividade do que para desenvolver ela./ Por quê? Porque a Grade Curricular, ela tem uma postura assim,/ acho que... meio..., meio de..., de tradicional né?!/ de você perpetuar um determinado conhecimento/ e, ainda que as coisas vão evoluindo,/ no ano seguinte você pode adotar um livro diferente..., um livro diferente e tal./ Mas, eu acho que a ementa dela, que um plano de ensino dela, de um modo geral/, o plano de ensino não,/ a ementa dela né?!/ eu acho que ela tem um sentido assim, mais de tolher a criatividadel do que propriamente estimulá-la/. A menos que você tenha disciplinas voltadas especificamente para isto né?!/ Até você falando agora, fazendo essa pergunta, me... me... surge a idéia de que...,/ quem sabe,/ poderíamos buscar alguém lá da área de Psicologia, né?!/..., pra dar uma disciplina optativa aqui no Curso,/ no último ano,/ sobre isso: o Desenvolvimento de Criatividade./ Adotar,/ quem sabe,/ esses livros que eu estou te falando,/ no sentido de desenvolver.../ Eu acho que isso dificulta o desenvolvimento dela./ É um conhecimento que você tem, de alguma forma, adquirir/. É uma série de regras, uma série de procedimentos que...,/ o que se move, o quê se ensina no Curso é o óbvio, né?!/ É aquilo que um profissional tem que ter,/ o mínimo que ele tem que ter,/ pra conseguir é... atuar depois no mercado.

No exemplo acima, foram destacados os registros com até quatro incidências, uma vez que estamos lidando com apenas um pequeno excerto do texto. Tenho mantido a apresentação de enunciados longos como "núcleos" só quando, após o cotejamento com a análise por palavras, fica demonstrado que não há perdas. Ou seja, aqui já estamos lidando com um gráfico que sintetiza os gráficos completos, nos quais todas as palavras com várias incidências, os núcleos, são contempladas na elaboração. 
No presente caso, as palavras e enunciados destacados foram:

04 - curso

04 - os outros/todo mundo/outra

04 - pensando/pensar

04 - sentido

05 - coisas

05 - desenvolver/desenvolvimento

05 - estou/tá

05 - mais

06 - Criatividade/ isso/ isto/ ela/ dela

06 - isso/de tolher/perpetuar um determinado conhecimento/tradicional/ dificultar

06 - não/nada

\section{7 - dela/isso/Grade Curricular/ela}

08 - acho

09 - Criativo/isso.

09 - tem/tenha

$11-\mathrm{Eu} / \mathrm{me}$

14 - dá soluções diferentes/enxergar uma coisa que a maioria das pessoas não conseguem enxergar/ solucionar coisas/ pensando as coisas não da maneira óbvia/ pensando de uma outra maneira/ de uma maneira mais eficaz/ mais interessante/ isso/ um conhecimento/ criar coisas/ tem, de alguma forma, adquirir/ uma série de regras, uma série de procedimentos que..., o que se move

\section{6 - você/se/te}

19 - é/Ser/ seja,

Com as palavras que se repetem ou seus sinônimos, é elaborado um gráfico, tal como no exemplo abaixo:

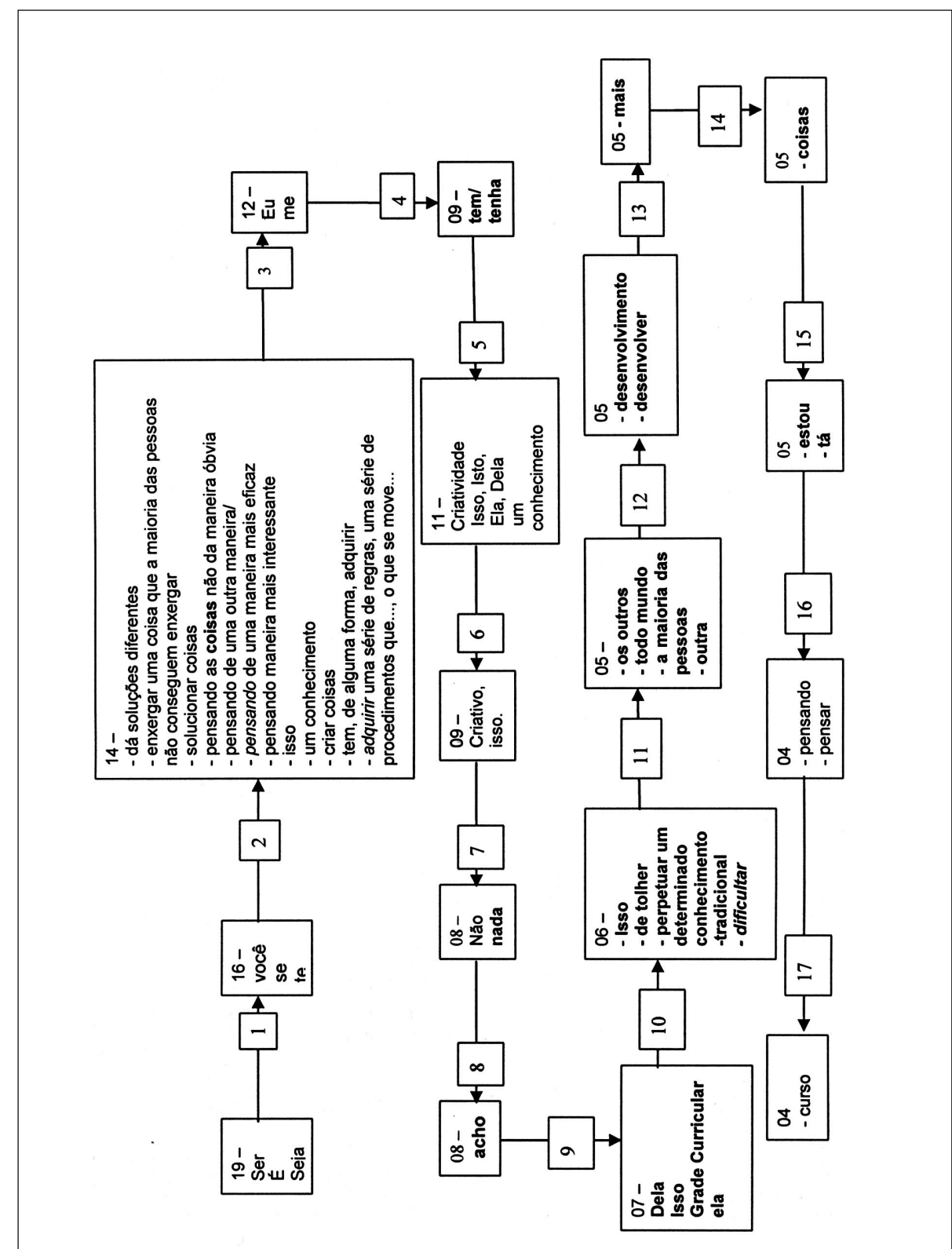


Este gráfico mostra os diferentes sentidos atribuídos à palavra, o que permite visualizar o movimento do pensamento, pois se conservam suas relações com o restante do discurso.

O gráfico nos oferece a idéia não desdobrada durante o discurso. Ou seja, o conteúdo condensado do qual nem o próprio sujeito teve consciência quando tentava elaborar o discurso sobre a temática. Neste caso este se revela da seguinte forma, após a reconstituição gráfica:

Seja você dá soluções diferentes, enxergar uma coisa que a maioria das pessoas não conseguem enxergar, solucionar coisas, pensando as coisas não da maneira óbvia, pensando de uma outra maneira, de uma maneira mais eficaz, mais interessante, um conhecimento; (para) criar coisas, tem(-se), de alguma forma, (que) adquirir uma série de regras, uma série de procedimentos que..., (são) o que se move, isso. Eu tenho um conhecimento, criatividade. Criativo não acho a grade curricular tradicional perpetuar um determinado conhecimento, dificultar os outros, todo mundo, a maioria das pessoas, desenvolver mais coisas, estou pensando (no) curso.

A partir desta identificação na Análise Gráfica dos Discursos dos entrevistados, realizamos a interpretação, buscando quais foram os conteúdos que se manifestaram a cada momento do processo de desdobramento da idéia em discurso verbal, comunicacional. Interessa-nos, principalmente, qual a influência das suas atividades neste e deste nas atividades que executaram em cada etapa do processo em estudo.

Quanto ao aspecto do pensamento, de apreensão lógica e histórico-conjuntural da realidade, é observado nas alterações dos significados dos Núcleos de Pensamento. Tanto no movimento transformacional ao longo do mesmo discurso, como na comparação das modificações ocorridas entre discursos de um mesmo sujeito.

Também é objeto de análise as semelhanças e diferenças das representações expressas por diferentes sujeitos envolvidos em um mesmo evento, uma vez que podem indicar a homogeneização da consciência social através da internalização da representação ideológica hegemônica.

Portanto, a partir dos textos gerados pelas transcrições das entrevistas, chamados também de 'corpo', as principais operações da análise são as seguintes: (a) uma decomposição do 'corpo' em unidades de significado segundo uma enumeração dos enunciados; (b) a elabo- ração dos gráficos; (c) a localização das palavras-núcleos; (c) a constituição de classes de equivalência semântica em função de um domínio de referência - os significados e sentidos expressos pelo movimento dos núcleos, indicados na Análise Gráfica.

Considerando que os dados da consciência nunca desvelam completa e diretamente as propriedades e tendências de todo o processo integral do qual formam parte, as relações entre os dados da autoconsciência e a consciência, entre os desta e os processos são idênticos às relações entre o fenômeno e a realidade.

Dentro da posição teórica que nos colocamos a consideração dos vários aspectos integrantes das palavras e das frases como estruturas de realização e concretização da atividade cognitiva e afetiva conduz à apreensão dos movimentos da consciência. Sobre os elementos assim apreendidos, podemos reconstruir os imbricamentos das funções, dos sistemas e dos processos utilizados para determinar a forma de constituição da identidade, com as formas da inserção social.

Portanto, buscamos, na exploração dos diálogos, a explicitação do processo em que se baseiam certas afirmativas acerca da relação entre pensamento e emoção. Entendemos, como Vigotsky (1987), que não há uma dicotomia entre o pensamento, a emoção e o comportamento; que a motivação e a emoção constituem a gênese do pensamento. E que tal como afirmou no seu famoso texto "Pensamento e linguagem":

O pensamento propriamente dito é gerado pela motivação, isto é, por nossos desejos e necessidades, nossos interesses e emoções. Por trás de cada pensamento, há uma tendência afetivo-volitiva, que traz em si a resposta ao último porquê de nossa análise do pensamento. Uma compreensão plena e verdadeira do pensamento de outrem só é possível quando entendemos sua base afetivo-volitiva. Para compreender a fala de outrem, não basta compreender as suas palavras, temos que entender o pensamento. Mas nem isso é suficiente - também é preciso que conheçamos a sua motivação.

\section{Referências}

Blanck, J. G. (1987). Teoria e método para uma ciência psicológica unificada. In M. Siguán (Ed.), Actualidad de Lev S. Vigotski. Barcelona, Espanha: Anthropos.

Lane, S. T. M. (1989). Uma Psicologia Social baseada no materialismo dialético: Da emoção ao inconsciente. In Anais do II Encontro Científico da Associação Nacional de Pesquisa e Pós-Graduação em Psicologia, Gramado, RS.

Lane, S. T. M., \& Codo, W. (Eds.). (1987). Psicologia Social: $O$ homem em movimento. São Paulo: Brasiliense.

Lane, S. T. M., \& Sawaia, B. (Eds.). (1995). Novas veredas da Psicologia Social. São Paulo, SP: Brasiliense. 
Leão, I. B. (1989). Processo de consciência-influência na viabilização do assentamento fundiário Retirada da Laguna. Dissertação de Mestrado não-publicada, Universidade Federal do Mato Grosso do Sul, Campo Grande, MS.

Leão, I. B. (1999). Os professores universitários: A emoção e o pensamento em um trabalho intelectual institucionalizado. Tese de Doutorado não-publicada, Pontifícia Universidade Católica de São Paulo, SP.

Luria, A. R. (1992). A construção da mente. São Paulo, SP: Ícone.

Páez, D., Valencia, J., Morales, J. F., Sarabia, B., \& Ursua, N. (1992). Teoria y método en Psicologia Social. Barcelona, España: Anthropos.

Sawaia, B. (2002). Sílvia Lane. Rio de Janeiro, RJ: Imago.

Vigotsky, L. S. (1972). Psicologia del Arte. Barcelona, Espanã: Barral.

Vigotsky, L. S. (1987). Pensamento e linguagem. São Paulo, SP: Martins Fontes.

Vigotsky, L. S. (1988). A formação social da mente (2. ed.). São Paulo, SP: Martins Fontes.

Vigotsky, L. S. (1991). Obras Escogidas: Vol. 1. Madrid, España: Centro de Publicaciones del MEC y Visor Distribuciones.

Vigotsky, L. S. (1993). Obras Escogidas: Vol. 2. Madri, España: Visor Distribuciones.

Inara Barbosa Leão é Psicóloga, Doutora em Psicologia (Psicologia Social) pela Pontifícia Universidade Católica de São Paulo (PUC-SP). Professora no Ensino de $3^{\circ} \mathrm{Grau,}$

na Universidade Federal de Mato Grosso do Sul, nos cursos de Graduação em Comunicação Social/Jornalismo e Formação de Psicólogo. Professora nos Cursos de Pós-

Graduação de Mestrado e Doutorado em Educação na Universidade Federal de Mato Grosso do Sul (UFMS).

Coordenadora das pesquisas: "Implicações Psicossociais do Desemprego para a Consciência Individual: manifestação no pensamento e emoção"; "O

desenvolvimento humano e a educação na perspectiva da

Teoria Socio-Histórica", "Trabalho e subjetivação em uma instituição hospitalar" e "Psicologia do Trabalho e suas interfaces com uma organização pública de

Assistência Social". Consultora do Programa Banco Social de Serviços em Psicologia do Conselho Federal de Psicologia para o Projeto de Apoio Psicológico ao Trabalhador em Situação de Desemprego. Consultora do Programa TEC NEP - MEC. Consultora para a elaboração das Diretrizes Curriculares de Psicologia da Educação, $2^{\circ}$ grau, parte diversificada, magistério. Secretária do Fórum de Entidades Nacionais da Psicologia. Brasileira, devido a sua condição de Presidente da Associação Brasileira de Ensino de Psicologia. 2003. Presidente da Associação Brasileira de Ensino de Psicologia - ABEP - 2003-2005

Endereço para correspondência: UFMS, Centro de Ciências Humanas e Sociais, Departamento de Ciências Humanas. Cidade Universitária, Caixa Postal 549, São Paulo, SP 79070-900. inarableao@hotmail.com
Um Método para Investigar a Consciência: do Intrapsicológico ao Interpsicológico

Inara Barbosa Leão

Recebido: 21/05/2007

Aceite final: 02/10/2007 